\title{
Nanocrystalline Magnetic Materials Obtained by Flash Annealing
}

\author{
R.K. Murakami, V. Villas-Boas* \\ Universidade de São Paulo, Instituto de Física, \\ C. P. 66318, 05315-970 São Paulo - SP, Brazil \\ *e-mail:val@macbeth.if.usp.br
}

Received: February 27, 1998; Revised: March 1, 1999

\begin{abstract}
The aim of the present work was to produce enhanced-remanence nanocrystalline magnetic material by crystallizing amorphous or partially amorphous $\operatorname{Pr} 4.5 \mathrm{Fe} 77 \mathrm{~B}_{18.5}$ alloys by the flash annealing process, also known as the dc-Joule heating process, and to determine the optimal conditions for obtaining good magnetic coupling between the magnetic phases present in this material. Ribbons of $\operatorname{Pr} 4.5 \mathrm{Fe} 77 \mathrm{~B} 18.5$ were produced by melt spinning and then annealed for $10-30 \mathrm{~s}$ at temperatures $500-640{ }^{\circ} \mathrm{C}$ by passing current through the sample to develop the enhanced-remanence nanocrystalline magnetic material. These materials were studied by X-ray diffraction, differential thermal analysis and magnetic measurements. Coercivity increases of up to $15 \%$ were systematically observed in relation to furnace-annealed material. Two different samples were carefully examined: (i) a sample annealed at $600{ }^{\circ} \mathrm{C}$ which showed the highest coercive field $\mathrm{H}_{\mathrm{c}}$ and remanence ratio $\mathrm{M}_{\mathrm{r}} / \mathrm{M}_{\mathrm{S}}$ and (ii) a sample annealed at $520{ }^{\circ} \mathrm{C}$ which showed phase separation in the second quadrant demagnetization curve. Our results are in agreement with other studies which show that flash annealing improves the magnetic properties of some amorphous ferromagnetic ribbons.
\end{abstract}

Keywords: nanocrystalline magnetic materials, flash annealing permanent magnets

\section{Introduction}

High performance permanent magnets require a material which can simultaneously have high remanence $\mathrm{M}_{\mathrm{r}}$, high Curie temperature $\mathrm{T}_{\mathrm{c}}$ and strong uniaxial anisotropy. Strnat and co-workers ${ }^{1}$ developed the well-known $\mathrm{SmCo}_{5}$ based material from which the first high performance permanent magnet was prepared and due to which, for example, the advent of the walkman was made possible. This material is made from aligned single crystal powders and presents the highest magnetocrystalline anisotropy of all known magnetic materials $\left(\mathrm{H}_{\mathrm{A}}=530-550 \mathrm{kOe}\right)^{2}$ which gives it high values for the coercive field $\left(\mathrm{H}_{\mathrm{c}}=20-40 \mathrm{kOe}\right)$ and energy product $\left((\mathrm{BH})_{\max } \approx 25 \mathrm{MGOe}\right)$. The coercive field $\mathrm{H}_{\mathrm{c}}$ and the energy product $(\mathrm{BH})_{\max }$ are usual measures of quality for permanent magnets. The coercive field $\mathrm{H}_{\mathrm{c}}$ is defined as the reverse field required to reduce the magnetization to zero. The $(\mathrm{BH})_{\max }$ is inversely proportional to the volume of permanent magnet material needed to produce a magnetic field in a given volume of space. So, the higher the $(\mathrm{BH})_{\max }$, the smaller the permanent magnetic device that can be produced. Despite the exceptional properties of this material, researchers continued to search for a rareearth - iron phase to replace the $\mathrm{SmCo}_{5}$ based material, because both samarium and cobalt are expensive and also because of instability in the cobalt market and the limited availability of separated samarium. In 1983, the ternary phase $\mathrm{Nd}_{2} \mathrm{Fe}_{14} \mathrm{~B}$ was announced at the same time in $\mathrm{Japan}^{3}$ and in the United States ${ }^{4}$. The $\mathrm{Nd}_{2} \mathrm{Fe}_{14} \mathrm{~B}$ phase is tetragonal and is magnetically uniaxial along the c-axis with $\mathrm{Nd}$ and Pr which are less expensive than $\mathrm{Sm}$. The $\mathrm{Nd}_{2} \mathrm{Fe}_{14} \mathrm{~B}$ phase also shows a saturation magnetization of about $16 \mathrm{kG}$ (due to the high iron content) which allow us to estimate values of 64 MGOe for $(\mathrm{BH})_{\max }$.

The high coercivity of NdFeB-type permanent magnet materials results, on the one hand, from the high anisotropy of the $\mathrm{Nd}_{2} \mathrm{Fe}_{14} \mathrm{~B}$ hard phase and, on the other hand, from the achievement, during the preparation process, of particular microstructures suitable to hinder the magnetization reversal. Sintering, melt-spinning and mechanical alloying are some of the techniques which have been used to produce $\mathrm{NdFeB}$ magnets. In all cases the microstructure is composed of individual grains of the hard magnetic phase and intergranular phases and precipitates which in general are non-magnetic. However, these microstructures are different with respect to the grain size and shape, imperfection in grains, phase composition and properties of intergranular 
phases. Typical average grain sizes are: 3 - $10 \mu \mathrm{m}$ for sintered magnets, $100 \mathrm{~nm}-1 \mu \mathrm{m}$ for melt-spun magnets and $300 \mathrm{~nm}-1 \mu \mathrm{m}$ for mechanically alloyed magnets.

Besides looking for different production techniques and suitable annealing treatments which may lead to optimal microstructures, the choice of an adequate alloy composition is desirable. The addition of various dopant elements to $\mathrm{NdFeB}$ magnets has also improved the magnet characteristics by changing the intrinsic magnetic properties of the main phase and the microstruture. For example: the substitution of $\mathrm{Co}$ for $\mathrm{Fe}$ increases the Curie temperature $\mathrm{T}_{\mathrm{c}}$; the substitution of Dy or Pr for $\mathrm{Nd}$ in the $\mathrm{NdFeB}$ magnets modifies the intrinsic magnetic properties of the main phase $\mathrm{Nd}_{2} \mathrm{Fe}_{14} \mathrm{~B}$ increasing the anisotropy field $\mathrm{H}_{\mathrm{A}}$ and consequently the $\mathrm{H}_{\mathrm{c}}$; the addition of $\mathrm{Ga}, \mathrm{Al}$ or $\mathrm{Cu}$ increases the viscosity of the intergranular nonmagnetic phase (during the liquid phase sintering process) that helps the magnetic decoupling of the grains.

Despite their magnetic and cost advantages, the $\mathrm{NdFeB}$ magnets have suffered because of their poor intrinsic corrosion resistance, since under humidity and temperature the $\mathrm{Nd}$-rich intergranular phase transforms into $\mathrm{Nd}(\mathrm{OH})_{3}$. One solution is to decrease the $\mathrm{Nd}$ content, so the lower rareearth content results in a better corrosion resistance of the magnets, because of the smaller amount of Nd-rich intergranular phase.

In the late 1980 s one of the most exciting additions to permanent magnet materials resulted from the discovery of the exchange spring magnets. These magnets are nanocrystalline materials consisting of a hard magnetic rare earthbased intermetallic, exchange-coupled to a soft magnetic phase. They have been the subject of much recent interest due to the possibility of their presenting enhanced remanence and large energy products in magnets containing large volume fractions of a soft magnetic phase. Enhanced remanence behavior $\left(\mathrm{M}_{\mathrm{r}} / \mathrm{M}_{\mathrm{s}}=0.75\right)$ was reported by Coehoorn et $a l^{5,6}$ in melt-spun and furnace-annealed alloys with compositions around $\mathrm{Nd}_{4} \mathrm{Fe}_{78} \mathrm{~B}_{18}$. This remanence value is higher than would be expected $\left(M_{r} / M_{s}=0.50\right)$ for a random collection of non-interacting particles with uniaxial anisotropy and it has been discussed ${ }^{7}$ in terms of two suitably dispersed and exchange-coupled ferromagnetic phases. In fact the nanocrystalline magnetic material reported by Coehoorn et al. ${ }^{5,6}$ is a more complex system composed of three phases: the main phase $\mathrm{Fe}_{3} \mathrm{~B}$, which is soft magnetic, representing aproximately $73 \%$ of the system; $\mathrm{Nd}_{2} \mathrm{Fe}_{14} \mathrm{~B}$ the hard magnetic phase which is $15 \%$ of the system; and $12 \%$ of $\alpha-\mathrm{Fe}$.

These nanocrystalline magnetic materials have some very important characteristics expected for a permanent magnetic material: (i) nanocrystalline grains whose size is of the order of a domain wall width; (ii) high iron content which generates high saturation magnetization values and makes the magnet much less expensive; and (iii) a low rare-earth content which leads to a better corrosion resistance of the magnets. In spite of these interesting properties, $\mathrm{NdFeB}$ nanocrystalline magnets suffer from one defect: they tend to have low $\mathrm{H}_{\mathrm{c}}$ values which in general are smaller than 3 kOe. In previous papers ${ }^{8-10}$ about nanocrystalline $\mathrm{R}_{4} \mathrm{Fe}_{78} \mathrm{~B}_{18}$, we tried to produce small grain (high coercivity) materials by rapid, high current crystallization of amorphous ribbons, the so called flash annealing process. The flash annealing process, also known as dc-Joule heating process, is a non-conventional annealing technique, characterized by a fast release of thermal energy to the material resulting from passing a current through the sample ${ }^{1-14}$. It induces the formation of non-equilibrium phases possibly displaying better physical properties with respect to furnace annealling. In the case of nanocrystalline $\mathrm{R}_{4} \mathrm{Fe}_{78} \mathrm{~B}_{18}$, we found that flash-annealed ribbons presented higher coercivities and higher remanence ratios than furnace-annealed ribbons, which shows that the flash annealing process enhances some properties of the enhanced-remanence nanocrystalline magnetic material ${ }^{8-10}$.

The aim of the present work was to produce enhancedremanence nanocrystalline magnetic material by crystallizing amorphous or partially amorphous $\operatorname{Pr}_{4.5} \mathrm{Fe}_{77} \mathrm{~B}_{18.5}$ alloys by the flash annealing process and to determine the optimal conditions for obtaining good magnetic coupling between the magnetic phases present in this material. The results obtained here are in agreement with other studies which show that the flash annealing process improves the magnetic properties of some amorphous ferromagnetic ribbons ${ }^{15-17}$.

\section{Experiment}

Partially amorphous ribbons of nominal composition $\mathrm{Pr}_{4.5} \mathrm{Fe}_{77} \mathrm{~B}_{18.5}$ were produced by melt-spinning in $\mathrm{He}$ on a mild steel wheel. X-ray diffraction of the as-cast ribbons with $\mathrm{CuK} \alpha$ radiation showed them to be partially amorphous. In previous papers ${ }^{9,10}$ about $\operatorname{Pr}_{4} \mathrm{Fe}_{78} \mathrm{~B}_{18}$, the initial ribbons were all partially amorphous and, even so, after the heat treatment, a good magnetic coupling was obtained for all the ribbons. From the Bragg reflection peak widths and the Scherrer equation, it was estimated that the crystallite size was of the order of $20 \mathrm{~nm}$.

In order to determine the temperatures where the flash annealing would be carried out, differential thermal analysis (DTA) measurements were performed for the as-cast ribbon at $10{ }^{\circ} \mathrm{C} / \mathrm{min}$. The results are presented in Fig. 1 and showed crystallization events beginning at $575{ }^{\circ} \mathrm{C}$ and $600{ }^{\circ} \mathrm{C}$, corresponding to crystallization of $\mathrm{Fe}_{3} \mathrm{~B}$ and $\operatorname{Pr}_{2} \mathrm{Fe}_{14} \mathrm{~B}^{6}$.

Since the ribbon dimensions (width 1-2 mm; thickness 30-40 $\mu \mathrm{m}$ ) were very regular it was possible to attach current and voltage leads directly to the sample with silver 


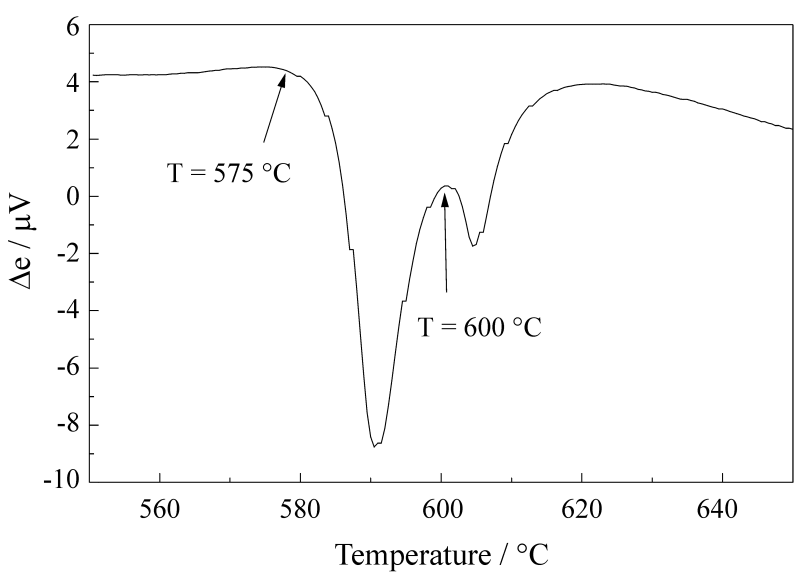

Figure 1. DTA measurement at $10{ }^{\circ} \mathrm{C} / \mathrm{min}$ for ribbon $\operatorname{Pr}_{4}{ }_{5} \mathrm{Fe}_{77} \mathrm{~B}_{18.5}$ showing crystallization events corresponding to $\mathrm{Fe}_{3} \mathrm{~B}$ and $\operatorname{Pr}_{2} \mathrm{Fe}_{14} \mathrm{~B}$.

paint for the flash annealing. The material itself was very uniform. For most of the samples, the initial resistivity was in the range $1.5-1.7 \mu \Omega \mathrm{m}$, while the resistivity after flash annealing was about $1.2-1.4 \mu \Omega \mathrm{m}$.

The experimental setup used for the flash annealing treatments is shown in Fig. 2. An electrical current of constant intensity supplied by a current generator flows through the sample (a ribbon of length $0.08-0.12 \mathrm{~m}$ ). The behaviour of the electrical resistance may be followed in the course of the heat treatment by simultaneously measuring the voltage across the sample and the electrical current flowing in it which are stored by the computer. The latter measurement is most conveniently performed by using a shunt in series with the ribbon. The sample holder was maintained in a diffusion pump vacuum in order to avoid surface oxidation. As a result, no convective processes are present, and the only sources of energy transfer from the flash annealed ribbon strip to the neighboring bodies are radiative losses and thermal conduction towards the sample holder through the electrical contacts. The annealings were carried out in a vacuum of $10^{-5}$ torr for times $10-30 \mathrm{~s}$ and for temperatures $500-640{ }^{\circ} \mathrm{C}$.

The sample temperature during the flash annealing was calculated from the following relation which is obtained by equating the Joule losses $\left(\mathrm{i}^{2} \mathrm{R}\right)$ with the radiated energy ${ }^{17}$, neglecting conduction through the current and voltage leads:

$$
\mathrm{T}_{\mathrm{a}}=\left(\mathrm{T}_{0}^{4}+\frac{\rho \mathrm{j}^{2}}{\mathrm{P}}\right)^{1 / 4}
$$

where $T_{0}$ is the ambient temperature, $\rho$ is the sample resistivity, $\mathrm{j}$ is the current density, and $\mathrm{P}$ is the loss parameter. The definition for $\mathrm{P}$ is

$$
\mathrm{P}=\frac{2 \varepsilon \sigma_{\mathrm{B}}}{\mathrm{d}}
$$



Figure 2. Experimental setup for the flash annealing process.

where $\varepsilon$ is the sample emissivity, $\sigma_{\mathrm{B}}$ is the StefanBoltzmann constant and $d$ is the ribbon thickness. In previous works ${ }^{9,10}$, considering the DTA measurements and the magnetization versus temperature measurements, we estimated for this ribbon $\varepsilon_{\text {eff }}=0.34-0.36$. These $\varepsilon_{\text {eff }}$ values are approximately equal to that encountered for pure iron in this temperature range. Finally, for our samples, a resistance bump was observed for all flash annealings at short times, since the additional power released by crystallization of the amorphous ribbon modifies the plateau temperature $^{18}$. It is the presence of this resistance bump which suggests a lower limit for annealing times of about $10 \mathrm{~s}$. In fact, for these $\operatorname{Pr}_{4.5} \mathrm{Fe}_{77} \mathrm{~B}_{18.5}$ samples the resistance bump lasts for about $8 \mathrm{~s}$, as shown in Fig. 3. For this reason we performed flash annealings during intervals of $30 \mathrm{~s}$ trying to assure that the crystallization process had been completed.

\section{Results and Discussion}

In order to determine the quality of the flash-annealed samples we did a careful study of all samples annealed at

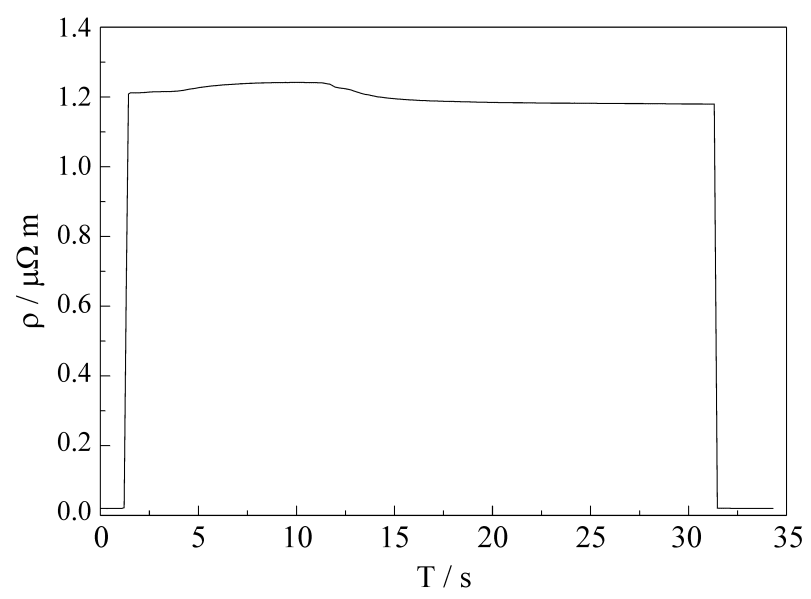

Figure 3. Resistance change $v s$. time for a flash annealing treatment performed in a sample. The resistance bump is due to crystallization of the sample. 
temperatures $500-640{ }^{\circ} \mathrm{C}$. We divided each sample into 11 pieces and we numbered them from 0 to 10 (the extremities being 0 and 10). We determined the hysteresis loops of these 11 pieces from which we determined their $\mathrm{H}_{\mathrm{c}}$ and their specific remanence $\sigma_{\mathrm{r}}$. (the remanence $\mathrm{M}_{\mathrm{r}}$, as well as any other magnetization value of the hysteresis curve, can be obtained by multiplying $\sigma_{\mathrm{r}}$ by $4 \pi$ and by the density of the material, which is $\rho=7.23 \mathrm{~g} / \mathrm{cm}^{3}$ for $\operatorname{Pr}_{4.5} \mathrm{Fe}_{77} \mathrm{~B}_{18.5}$ ). Figure 4 shows the $H_{c}$ and the ratio $\sigma_{\mathrm{r}} / \sigma_{\mathrm{s}}$ values $\left(\sigma_{\mathrm{s}}\right.$ is the specific saturation magnetization) for the various pieces of a sample which was flash-annealed at $640{ }^{\circ} \mathrm{C}$. For pieces 0 and 10 there are no values of $H_{c}$ and $\sigma_{r}$ because they are not magnetically coupled. This was expected since, in these current annealings, the sample ends are not really maintained at the annealing temperature because of thermal conduction towards the sample holder through the electrical contacts, as it was already mentioned. For all the other characterizations we only used the pieces numbered 1 to 9 .


Figure 4. Magnetic characterization for the pieces 1 to 9 of a sample which was flash-annealed at $640{ }^{\circ} \mathrm{C}$ : (a) $\mathrm{H}_{\mathrm{c}}$ values; (b) $\sigma_{\mathrm{r}} / \sigma_{\text {sat }}$ values.
Excellent magnetic coupling is observed for all samples annealed at temperatures $560-640^{\circ} \mathrm{C}$. For this temperature range there is a single well-defined peak in $\mathrm{d} \sigma / \mathrm{dH} . \mathrm{d} \sigma / \mathrm{dH}$ is the total susceptibility $\chi_{\text {tot }}$ and is approximately equal to the irreversible susceptibility $\chi_{\text {irr }}$ when the reversible susceptibility is small, which is the case of the materials studied in this work. In this work, the coercive field $\mathrm{H}_{\mathrm{c}}$ is defined as the field corresponding to the maximum of the irreversible susceptibility $\chi_{\text {irr }}$ (approximately the maximum in $d \sigma / d H)$, since $H_{c}$ is intimately related to the irreversible processes occuring in the magnetic material. This is the usual definition for those who work with coercivity mechanisms in permanent magnetic materials.

In Fig. 5 we show the specific magnetization $\sigma$ as a function of the applied magnetic field $\mathrm{H}$ for a sample which was flash-annealed at $600{ }^{\circ} \mathrm{C}$ for $30 \mathrm{~s}$. For this sample, which we will refer to the well-coupled sample $\mathrm{WC}$, we obtained the best magnetic properties, which are $\mathrm{H}_{\mathrm{c}}=4.3$ kOe and $M_{r} / M_{s}=0.72$. For the samples which were flashannealed at temperatures lower than $560{ }^{\circ} \mathrm{C}$, the magnetic coupling between phases deteriorated and two peaks were observed in $\chi_{\text {irr. }}$ In Fig. 5 we also show the specific magnetization $\sigma$ as a function of the applied magnetic field $H$
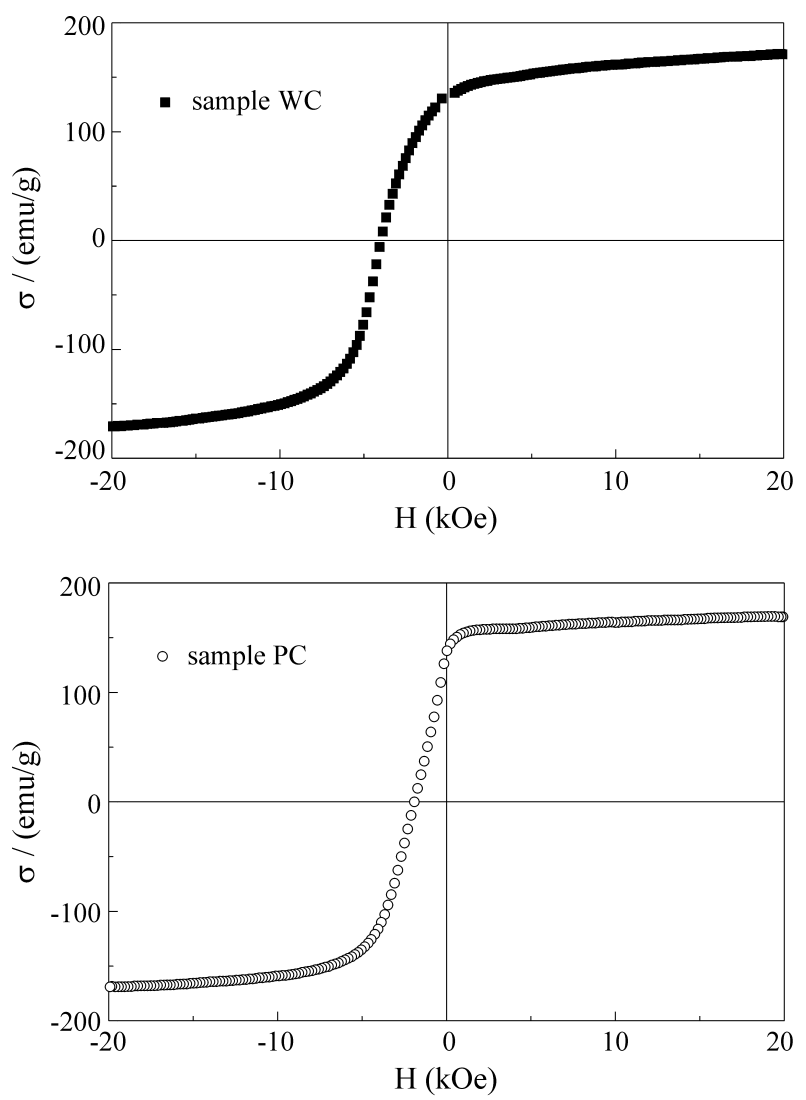

Figure 5. Specific magnetization $\sigma$ vs. applied field $\mathrm{H}$ for WC sample and $\mathrm{PC}$ sample undergoing $30 \mathrm{~s}$ flash annealing. 
for a sample which was flash-annealed at $520{ }^{\circ} \mathrm{C}$ for $30 \mathrm{~s}$ and that we will refer to as the partially-coupled sample PC.

In Fig. 6 we show $\mathrm{d} \sigma / \mathrm{dH} \cong \chi_{\text {irr }}$ for samples $\mathrm{WC}$ and PC. The decoupling of the magnetic phases in sample PC can be seen very clearly from two peaks in $\chi_{\text {irr }}$, the larger corresponding to $\mathrm{H}_{\mathrm{c}}=2.8 \mathrm{kOe}$ and the smaller to $\mathrm{H}_{\mathrm{c}}=0.8$ $\mathrm{kOe}$. In the other hand, for sample WC there is a single, well-defined peak in $\chi_{\text {irr }}$ corresponding to $\mathrm{H}_{\mathrm{c}}=4.3 \mathrm{kOe}$.

The $\mathrm{H}_{\mathrm{c}}$ data for all the samples studied in this work are presented in Fig. 7 as a function of the flash annealing temperature $\mathrm{T}_{\mathrm{a}}$, the highest value of $\mathrm{H}_{\mathrm{c}}=4.3 \mathrm{kOe}$ being obtained for $\mathrm{T}_{\mathrm{a}}=600{ }^{\circ} \mathrm{C}$. There is a temperature range $(560$ - $640{ }^{\circ} \mathrm{C}$ ) for which the magnetic coupling is sufficient to give a single peak in $\chi_{\text {irr }}$ as mentioned above. For temperatures lower than $560{ }^{\circ} \mathrm{C}$ the phases are clearly decoupled or present low values of $\mathrm{H}_{\mathrm{c}}$. We did not investigate annealing temperatures higher than $640{ }^{\circ} \mathrm{C}$.

Although we achieved good magnetic coupling and high $\mathrm{H}_{\mathrm{c}}$ for samples which were flash annealed at temperatures $560-640{ }^{\circ} \mathrm{C}$, the results obtained for the samples annealed at 560 and $580{ }^{\circ} \mathrm{C}$ suggest that the sample temperature which was calculated from relation (1) may not be


Figure 6. Irreversible susceptibility $\chi_{\text {irr }} v s$. applied field $\mathrm{H}$ for samples WC and PC, flash-annealed at 600 and $520^{\circ} \mathrm{C}$ respectively for $30 \mathrm{~s}$. the real annealing temperature. The DTA results show that the crystallization event due to the hard magnetic phase $\operatorname{Pr}_{2} \mathrm{Fe}_{14} \mathrm{~B}$ begins at $600{ }^{\circ} \mathrm{C}$. Therefore, we must understand why, even $40{ }^{\circ} \mathrm{C}$ below this crystallization temperature, the nanocrystalline magnetic material still shows high $\mathrm{H}_{\mathrm{c}}$ which indicates the presence of the $\operatorname{Pr}_{2} \mathrm{Fe}_{14} \mathrm{~B}$ phase. This may indicate that the real annealing temperature is higher than the temperature calculated from Eq. 1. In order to clarify this question and also to complete the magnetic characterization of the sample, we performed measurements of the dependence of the magnetization with the temperature. These measurements can show us the magnetic phases present in the samples. In Fig. 8 we show the thermal magnetic results for sample WC and sample PC. For sample WC we can identify two magnetic phases which are the $\operatorname{Pr}_{2} \mathrm{Fe}_{14} \mathrm{~B}$ phase whose Curie temperature is around $300{ }^{\circ} \mathrm{C}$ and the $\mathrm{Fe}_{3} \mathrm{~B}$ phase whose Curie temperature is around $500{ }^{\circ} \mathrm{C}$. For sample $\mathrm{PC}$ we can identify three magnetic phases which are the $\operatorname{Pr}_{2} \mathrm{Fe}_{14} \mathrm{~B}$ phase, the $\mathrm{Fe}_{3} \mathrm{~B}$ phase and the $\operatorname{Pr}_{2} \mathrm{Fe}_{23} \mathrm{~B}_{3}$ whose Curie temperature is around $380{ }^{\circ} \mathrm{C}$. Although temperatures higher than $600{ }^{\circ} \mathrm{C}$ cannot be achieved by our resistive furnace where the measurements are performed, we can see that, in both samples, a residual magnetization due to $\alpha-\mathrm{Fe}$, whose Curie temperature is around $770{ }^{\circ} \mathrm{C}$, can be detected.

From the measurements of dependence of the magnetization with the temperature we found the presence of the $\operatorname{Pr}_{2} \mathrm{Fe}_{14} \mathrm{~B}$ phase which confirmed our suspicion that the real annealing temperature is higher than the temperature calculated from Eq. 1. Looking carefully at Eqs. 1 and 2 we see that the calculated temperatures $\mathrm{T}_{\mathrm{a}}$ would be higher if we had a smaller emissivity $\varepsilon$. However, determining the emissivity of this material is not a straightforward and trivial thing to do. Standard handbooks ${ }^{19}$ show that the emissivity of iron varies with temperature and the wavelenght (at $\mathrm{T}=800{ }^{\circ} \mathrm{C}$ if $\lambda=0.65 \mu \mathrm{m} \varepsilon=0.37$ and if $\lambda=1.2$ $\mu \mathrm{m} \varepsilon=0.29$ ). No data is avaiable for praseodymium or

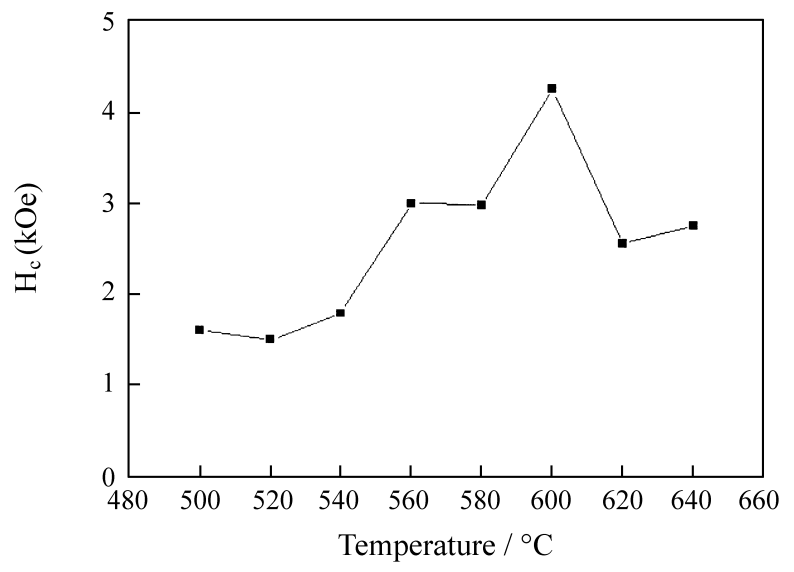

Figure 7. Coercive field $\mathrm{H}_{\mathrm{c}} v s$. flash-annealing temperature $\mathrm{T}_{\mathrm{a}}$ for $30 \mathrm{~s}$ anneal for all samples studied. 
boron and, therefore, we are unable to estimate an average value for the emissivity of our material. What is more, a change of 0.06 in the emissivity can change the calculated temperature $\mathrm{T}_{\mathrm{a}}$ by $40^{\circ} \mathrm{C}$, exactly the difference we need to explain the presence of the $\operatorname{Pr}_{2} \mathrm{Fe}_{14} \mathrm{~B}$ phase in a sample flash-annealed at $560{ }^{\circ} \mathrm{C}$.

The problem of determining accurately the annealing temperature remains. One procedure which could be used at present would be to present the properties of the material as a function of the annealing current without specifying the temperature. This procedure has been used by some researchers, since they are more interested in the improvement of the proprietiers due to thermal treatment rather than the real temperature where the thermal treatment was performed $^{20}$.

Finally, it is useful to try to understand why $\mathrm{H}_{c}$ is higher in the flash-annealed materials than in the conventionally annealed ones. For that we could say something about the microstructure of the ribbons. In previous works ${ }^{8-10}$ we showed that the flash annealing of $\mathrm{Nd}_{4} \mathrm{Fe}_{78} \mathrm{~B}_{18}$ results in a phase distribution which is different from that encountered in materials prepared by conventional furnace anneals. X-ray diffraction and Mössbauer spectroscopy data showed


Figure 8. Specific magnetization $v s$. temperature $\mathrm{T}$ for samples $\mathrm{WC}$ and PC. that flash annealing resulted in significant amounts of $\mathrm{Nd}_{2} \mathrm{Fe}_{23} \mathrm{~B}_{3}$, a metastable cubic phase, and reduced quantities of $\alpha$-Fe. TEM measurements ${ }^{21}$ on a ribbon of furnaceannealed $\mathrm{Nd}_{4} \mathrm{Fe}_{78} \mathrm{~B}_{18}$ showed the presence of a matrix phase consisting of 20 - $30 \mathrm{~nm}$ equiaxed grains with $\mathrm{Fe} / \mathrm{Nd}$ $=17$ - 19.6. Also observed was a second phase precipitate consisting of large $(\approx 60-100 \mathrm{~nm})$ grains with $\mathrm{Fe} / \mathrm{Nd}=$ 43.8. Electron diffraction indicated an interplanar spacing close to that of $\alpha$-Fe. For flash-annealed $\mathrm{Nd}_{4} \mathrm{Fe}_{78} \mathrm{~B}_{18}$ showing phase separation, the matrix phase consisted of 30 $50 \mathrm{~nm}$ equiaxed grains. In this case, the second phase precipitate had a glassy-like morphology. For a ribbon of $\mathrm{Nd}_{4} \mathrm{Fe}_{78} \mathrm{~B}_{18}$ whose hysteresis loop showed good coupling of the magnetic phases, the large $\alpha$-Fe grains were completely absent and only the $\approx 20 \mathrm{~nm}$ equiaxed grains were observed. If we suppose that the large $\alpha$-Fe grains facilitate magnetization inversion in furnace-annealed material, then their elimination in well-coupled flash-annealed samples would explain the increased $\mathrm{H}_{\mathrm{c}}$ observed for both $\mathrm{Nd}_{4} \mathrm{Fe}_{78} \mathrm{~B}_{18}$ and $\mathrm{Pr}_{4} \mathrm{Fe}_{78} \mathrm{~B}_{18}$. On the other hand, flash-annealed $\mathrm{Nd}_{4} \mathrm{Fe}_{78} \mathrm{~B}_{18}$ showed a significantly higher remanence ratio $\left(\mathrm{M}_{\mathrm{r}} / \mathrm{M}_{\mathrm{s}}=0.83\right)$ than the furnace-annealed material $\left(\mathrm{M}_{\mathrm{r}} / \mathrm{M}_{\mathrm{s}}=0.74\right)$. For $\operatorname{Pr}_{4} \mathrm{Fe}_{78} \mathrm{~B}_{18} \mathrm{M}_{\mathrm{r}} / \mathrm{M}_{\mathrm{s}}=0.77$ for both furnace and flash annealed samples ${ }^{9,10}$. Thus we cannot assume that the same microstructural differences exist between furnace and flash annealed $\operatorname{Pr}_{4} \mathrm{Fe}_{78} \mathrm{~B}_{18}$ and for our $\operatorname{Pr}_{4.5} \mathrm{Fe}_{77} \mathrm{~B}_{18.5}$. Further microstructural investigations such as TEM and AFM in our $\operatorname{Pr}_{4.5} \mathrm{Fe}_{77} \mathrm{~B}_{18.5}$ are necessary.

\section{Conclusions}

We have used the flash annealing process to crystallize partially amorphous ribbons of $\operatorname{Pr}_{4.5} \mathrm{Fe}_{77} \mathrm{~B}_{18.5}$ producing enhanced-remanence nanocrystalline magnetic material. The optimal conditions for obtaining good magnetic coupling between the magnetic phases present in this material were established. The coercive field $\mathrm{H}_{\mathrm{c}}$ for these flash-annealed material increases up to $15 \%$ compared to the values reported in the literature to furnace-annealed material ${ }^{9}$ showing that this kind of current treatment really generates materials with better magnetic properties with respect for conventionally annealed ones. Then we can conclude that our results are in agreement with other studies which show that flash annealing improves the magnetic properties of some amorphous ferromagnetic ribbons.

\section{Acknowledgements}

The authors acknowledge S.A. Romero for helping with the preparation of the melt-spun ribbons; F.P. Missell for useful conversations and for the careful reading of the manuscript; and the financial support of FAPESP, CNPq, and FINEP. 


\section{References}

1. Strnat, K.; Hoffer, G.; Olson, J.; Ostertag, W.; Becker, J.J. J. Appl. Phys., n. 38, p. 1001, 1967.

2. Campos, M.F.; Landgraf, F.J.G.; Saito, N.H.; Romero, S.A.; Neiva, A.C.; Missell, F.P.; Obrucheva, E.V.; Jalnin, B.V.; de Morais, E.; Gama, S. J. Appl. Phys., n. 84, p. 368, 1998.

3. Sagawa, M.; Fujirama, S.; Yamamoto, H.; Hiraga, K. IEEE Trans. Magn., n. 20, p. 1584, 1984.

4. Croat, J.J.; Herbst, J.F.; Lee, R.W.; Pinkerton, F.E. J. Appl. Phys., n. 55, p. 2079, 1984.

5. Coehoorn, R.; de Mooij, D.B.; Duchateau, J.P.W.B.; Buschow, K.H.J. J. de Phys., n. 49, p. C8-669, 1988.

6. Coehoorn, R.; de Mooij, D.B.; de Waard, C. J. Magn. Magn. Mater., n. 80, p. 101, 1989.

7. Kneller, E.F.; Hawig, R. IEEE Trans. Magn., n. 27, p. 3588, 1991.

8. Altoé, M.V.P.; Lancarotte, M.S.; Rechenberg, H.R.; Missell, F.P.; González, J.M. IEEE Trans. Magn., n. 31, p. 3614, 1995.

9. Villas-Boas, V., Romero, S.A.; Missell, F.P. Magnetic Anisotropy and Coercivity in Rare-Earth Transition Metal Alloys, Missell, F.P.;Villas-Boas, V.; Rechenberg, H.R.; Landgraf, F.J.G., eds, World Scientific, Singapore, 31, 1996.
10. Villas-Boas, V.; Romero, S.A.; Missell, F.P. J. Appl. Phys., n. 81, p. 4434, 1997.

11. Yavari, A.R.; Barrue, R.; Harmelin, M.; Perron, J.C. J. Magn. Magn. Mater., n. 69, p. 43, 1987.

12. Kulil, T.; Matyja, H. Mater. Sci. Eng. A, n. 133, p. 232, 1991.

13. Gibbs, M.R.J.; Lee, D.H.; Evetts, J.E., IEEE Trans. Magn., n. 20, p. 1373, 1984.

14. Matyja, H.; Zaluska, A. Philos. Mag. B, n. 61, p. 701, 1990.

15. Warlimont, H. Rapidly Quenched Metals, Steeb, S.; Warlimont, H., eds, North-Holland, Amsterdam, p. 1599, 1985.

16. Luborsky, F.E. Amorphous Metallic Alloys, Luborsky, F.E., ed., Butterworths, London, 1, 1983.

17. Allia, P.; Tiberto, P.; Baricco, M.; Vinai, F. Rev. Sci. Instrum., n. 64, p. 1053, 1993.

18. Knobel, M.; Allia, P.; Gómez-Polo, C.; Chiriac, H.; Vázquez, M. J. Phys. D: Appl. Phys., n. 28, p. 2398, 1995.

19. Smithells Metals Reference Book, Brandes, E.A., ed., Butterworths, London chapter 17, 1983.

20. Ferrari, E.F.; da Silva, F.C.S.; Knobel, M. Phys. Rev. $B$, n. 56, p. 6086, 1997.

21. Altoé, M.V.P.; Echer, C.E.; Thomas, G. Nanostructured Mater., n. 8, p. 19, 1997. 